\title{
Optimistic Goal: Whether Possible or Tenable for Thailand?
}

ISSN: 2689-2707

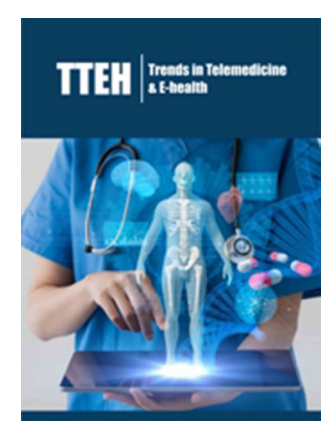

*Corresponding author: Somchai Bovornkitti, Emeritus Professor of Medicine, Fellow of the Academy of Science, The Royal Society of Thailand, Thailand

Submission: 酱 August 26, 2019

Published: 眥 September 04, 2019

Volume 2 - Issue 1

How to cite this article: Somchai Bovornkitti. Optimistic Goal: Whether Possible or Tenable for Thailand?. Trends Telemed E-Health 2(1). TTEH. 000526. 2019. DOI: 10.31031/TTEH.2019.02.000526

Copyright@ Somchai Bovornkitti, This article is distributed under the terms of the Creative Commons Attribution 4.0 International License, which permits unrestricted use and redistribution provided that the original author and source are credited.

\section{Somchai Bovornkitti* \\ Emeritus Professor of Medicine, Thailand}

\section{Opinion}

For the record, most welcome news is contained in a recent official statement of the Parliamentary Under Secretary of State for Public Health and Primary Care of the United Kingdom: it has set an ambition for England to go "smoke-free" by the year 2030. This ambition has been encouraged by epidemiological data showing a progressive decline in the prevalence of adult cigarettes smoking in the country since 2011 (Figure 1).

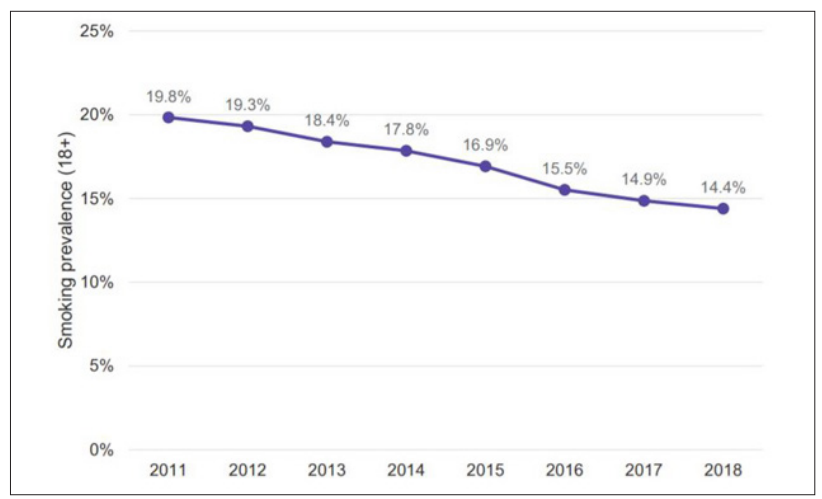

Figure 1: Adult smoking prevalence in England, 2011 to 2018.

From the author's perspective, that optimistic decline is occurring automatically in England, and not because of human intervention. The progressive decline in the incidence of smoking might actually be due to the growing knowledge among the populations of highly developed countries, such as the United Kingdom, with regard to health and such hazardous activities as drinking and smoking, and hence the desire to cease such activities [1].

Notwithstanding the above, such a decline in the incidence of smoking is not likely to occur in Thailand without the imposition of strong measures to stop tobacco smoking in the country, perhaps such as those taken many decades ago to ban opium smoking in Thailand.

\section{References}

1. (2019) Adults smoking habits in the UK: 2018. Office for National Statistics, Annual Population Survey, UK. 